\title{
Os arquivos pessoais de Gilda de Mello e Souza e Antonio Candido
}

\author{
[ The personal archives of Gilda de Mello e Souza and Antonio Candido
}

\author{
Elisabete Marin Ribas ${ }^{\mathrm{I}}$
}

\section{Laura Escorel ${ }^{2}$}

RESUMO - Doados ao Instituto de Estudos Brasileiros da Universidade de São Paulo em 20I7, os arquivos de Gilda e Antonio Candido de Mello e Souza começam a ter seus dados abertos ao acesso público no segundo semestre de 2020 . O presente trabalho tem por objetivo compartilhar a experiência do tratamento técnico aplicado aos arquivos dos professores e apresentar o conteúdo dos fundos e alguns dos instrumentos de pesquisa elaborados, convidando os interessados na vida e na obra dos titulares da documentação ao desenvolvimento de futuras pesquisas.

- PAlaVRAS-CHAVE - Gilda de Mello e Souza; Antonio Candido; arquivos pessoais; arquivos de casais. - ABSTRACT - Donated to the Institute of Brazilian Studies at the University of São Paulo in 20I7, the personal archives of Gilda and Antonio Candido de Mello e Souza will be open to public access in the second half of 2020 . The present work aims to share the experience of the technical treatment applied to the teachers' records and to present the content of the funds and some of the research instruments produced, inviting those interested in the life and work of the documentation holders the development of future research. KEYWORDS - Gilda de Mello e Souza; Antonio Candido; personal archives; couple's personal archives.

Recebido em I3 de julho de 2020

Aprovado em 28 de julho de 2020

RIBAS, Elisabete Marin; ESCOREL, Laura. Os arquivos pessoais de Gilda de Mello e Souza e Antonio Candido. Revista do Instituto de Estudos Brasileiros, Brasil, n. 76, p. 275-289, ago. 2020.

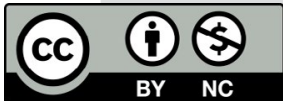

DOI: https://doi.org/Io.II6o6/issn.23I6-90IX.vIi76p275-289

1 Universidade de São Paulo (USP, São Paulo, SP, Brasil).

2 Universidade Federal de São Paulo (Unifesp, São Paulo, SP, Brasil). 
Doados ao Instituto de Estudos Brasileiros da Universidade de São Paulo (IEB/USP), em dezembro de 20I7, por Ana Luisa Escorel, Laura de Mello e Souza e Marina de Mello e Souza, filhas do casal, os arquivos pessoais de Gilda e Antonio Candido receberam um tratamento bastante minucioso, mesmo antes de sua transferência. Ainda em 20I5, a pedido da família, Laura Escorel, uma das autoras deste ensaio, iniciou, em diálogo com Antonio Candido, um trabalho de levantamento da documentação iconográfica. Na ocasião, Candido expressava o desejo de que aquelas fotografias fossem depositadas em uma instituição de guarda, formando assim um Arquivo Gilda e Antonio Candido 3 .

Com a morte de Antonio Candido, em maio de 20I7, e respeitando a sua própria orientação de que seus papéis de trabalho fossem entregues ao IEB/USP, foi acordado que o procedimento mais pertinente seria entregar os arquivos pessoais de ambos os professores integralmente a essa instituição, incluindo na doação, além da documentação textual, os documentos iconográficos, sonoros e audiovisuais. Assim, desde esse primeiro momento se impôs uma questão de base: como seriam tratados esses acervos, como um arquivo único e indivisível de um casal ou como dois arquivos separados e autônomos?

Considerando a atuação significativa que os professores Antonio Candido e Gilda de Mello e Souza tiveram em suas áreas, o rigor científico e a demanda de tempo que o trabalho com arquivos pessoais exige e a expectativa dos pesquisadores de terem acesso aos documentos, estabeleceu-se uma parceria com o Instituto Itaú Cultural, que proveu a contratação de uma equipe interdisciplinar e de consultorias especializadas, bem como a aquisição de material de acondicionamento adequado, permitindo assim

3 Quanto à questão da nomeação do arquivo, seja apenas a parte iconográfica, seja o acervo como um todo, cabe dizer que a preocupação de Antonio Candido era de que o arquivo pessoal de Gilda recebesse os mesmos cuidados que o seu, assim como o mesmo empenho no que diz respeito às ações de difusão. 
realizar o tratamento do arquivo em um espaço de tempo relativamente curto e, consequentemente, abreviando a sua abertura para a pesquisa pública ${ }^{4}$.

Embora atentos à orientação de Antonio Candido de que o arquivo de Gilda recebesse os mesmos cuidados e empenho na difusão que o seu, no processo de institucionalização do arquivo foram redigidos dois termos de doação, um relativo ao Fundo Antonio Candido e outro relativo ao Fundo Gilda de Mello e Souza. No que diz respeito ao tratamento técnico, os arquivos foram organizados como dois fundos distintos por duas razões: I) o mapeamento do arquivo no apartamento do casal permitiu identificar com bastante nitidez os conjuntos que pertenciam a cada um dos titulares, com exceções que serão descritas na conclusão deste artigo e sobre as quais trata a pesquisa de doutorado de Elisabete Marin Ribas, uma das autoras deste texto; 2) a prática dos especialistas em organização de arquivos pessoais, tanto da equipe contratada, quanto dos funcionários do IEB/USP, sempre foi a de organizar os fundos de forma individualizada, e seguir com a metodologia habitual agilizaria os processos de abertura ao público.

Os trabalhos de tratamento documental dos fundos Gilda de Mello e Souza e Antonio Candido foram coordenados pelas autoras e a partir de agora passam a ser apresentados com dois intuitos: I) compartilhar a experiência com interessados na metodologia de organização de arquivos pessoais à luz das teorias arquivísticas; 2) apresentar ao estudioso interessado na vida e na obra dos titulares da documentação parte dos instrumentos de pesquisa elaborados e, consequentemente, o conteúdo presente nos fundos, convidando-o para o desenvolvimento de futuras pesquisas.

\section{O Fundo Gilda de Mello e Souza}

Lançando mão das palavras de Heloísa Pontes acerca dos dados biográficos de Gilda, destacamos:

Gilda de Mello e Souza firmou-se como intelectual na intersecção da influência do "papa" do modernismo paulista, Mário de Andrade, seu primo em segundo grau, com a formação universitária que recebeu na Faculdade de Filosofia, Ciências e Letras da

4 O tratamento do arquivo pessoal de Gilda de Mello e Souza e Antonio Candido foi iniciado em dezembro de 20I7, ainda no apartamento do casal, no qual foi realizado o mapeamento do material e, posteriormente, a reprodução digital da documentação iconográfica. Em abril de 2018 foi iniciado o tratamento do arquivo, agora nas dependências do Arquivo IEB/USP, com o processo de higienização seguido pelas etapas de reparos e estabilização, classificação, descrição e acondicionamento. A conclusão do trabalho, prevista para julho de 2020, foi adiada em função da pandemia da covid-I9. Ainda assim, a grande maioria dos documentos já se encontra cadastrada no Sistema de Gerenciamento do Arquivo-IEB (SGA), que é o banco de dados da instituição, para consulta de descritores disponíveis on-line no site do IEB. No momento da escrita deste ensaio, constam, no SGA, 6.590 documentos cadastrados no Fundo Gilda de Mello e Souza e 2I.406 documentos no Fundo Antonio Candido, restando apenas 20 caixas do arquivo textual de Gilda e 25 caixas do arquivo textual de Antonio Candido a serem cadastradas. 
Universidade de São Paulo. Intelectual de perfil acadêmico, sua marca encontra-se em seus ensaios e livros [...]. (PONTES, 20Io, p. II6).

A citação foi selecionada porque traz algumas informações importantes para o desenvolvimento de nossa argumentação, dentre as quais elencamos: I) a proximidade de Gilda com Mário de Andrade; 2) seu trabalho intelectual, com especial destaque para seus ensaios e livros. Esses dois pontos foram norteadores para algumas das decisões de classificação de sua documentação, pois tanto Mário de Andrade, quanto os ensaios de Gilda caracterizam parte significativa dos documentos presentes em seu fundo pessoal.

É sempre importante lembrar que arquivos pessoais, "também considerados arquivos privados propriamente ditos" são "papéis e material audiovisual ou iconográfico resultante da vida e da obra/atividade” (BELLOTTO, 2006, p. 265, 266 - grifo nosso) de determinada pessoa e que, acumulados durante anos, quando organizados a partir dos princípios arquivísticos, refletem as funções exercidas pelo titular da documentação. Às equipes que trabalham com fundos pessoais, cabe o exercício de partir dos documentos presentes no arquivo para estruturar sua classificação, tendo como base o contexto de produção de tais documentos, naquilo que chamamos de método funcional. Idealizado por Ana Maria Camargo, tal método tem sido aplicado predominantemente nos últimos dez anos pelo corpo técnico do Arquivo IEB/USP, com adaptações realizadas considerando tanto a estrutura institucional quanto o público pesquisador que nos busca.

O caso do Fundo Gilda de Mello e Souza não foi diferente. É claro que as particularidades dos arquivos pessoais, atreladas às especificidades da vida da titular da documentação, são desafios a serem considerados. Como nos lembram Ana Maria Camargo e Silvana Goulart,

No âmbito dos arquivos pessoais, [...] as fronteiras que demarcam as diferentes áreas de ação de um mesmo indivíduo são tênues e imprecisas. O uso do método funcional, além de imperativo, demanda a identificação das atividades imediatamente responsáveis pelos documentos [...]. (CAMARGO; GOULART, 2007, p. 23-24).

Para explicarmos a metodologia de classificação, faz-se necessário um pequeno recuo, retornando ao momento de doação e consequente retirada do acervo. $\mathrm{O}$ arquivo pessoal de Gilda de Mello e Souza permaneceu sob responsabilidade de Antonio Candido, que não só manteve o acervo sob seus cuidados, como também buscou organizá-lo por meio de pastas, envelopes, etiquetas e notas explicativas (Figura I) que identificavam os documentos. 


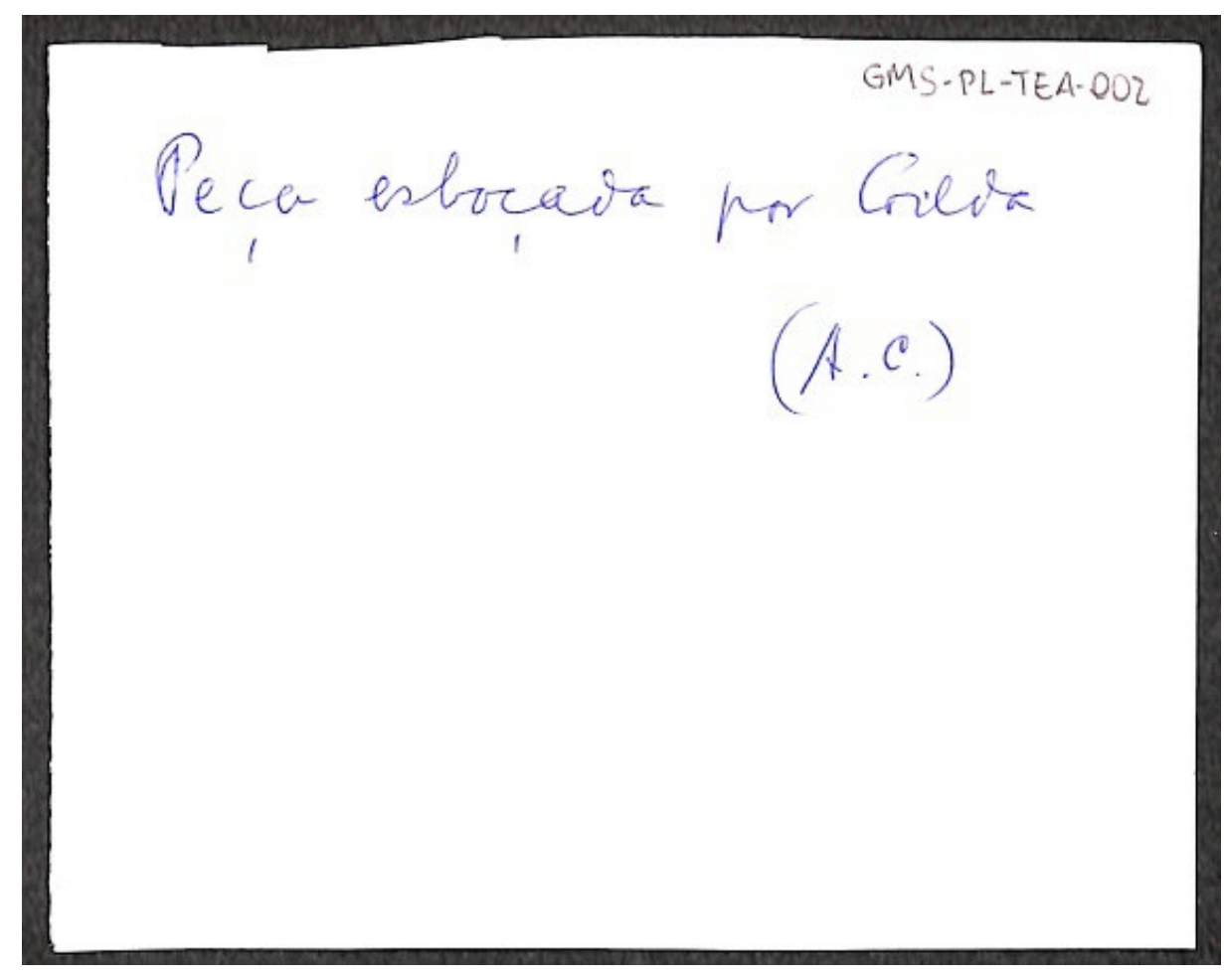

Figura I - Exemplo de nota explicativa deixada por Antonio Candido. Arquivo IEB/USP, Fundo Gilda de Mello e Souza, código de referência GMS-PL-TEA-002

Entendemos que Antonio Candido buscou compartilhar seu conhecimento prévio sobre os documentos de Gilda, deixando informações aos futuros responsáveis pela custódia e organização do arquivo. Além disso, os documentos de Gilda, durante a guarda doméstica feita por Antonio Candido, foram reunidos em um único armário, restando fora dele, em uma escrivaninha, apenas alguns conjuntos, como fichas e poucas outras tipologias documentais acomodadas predominantemente em gavetas. Também ficaram fora do armário conjuntos de fotografias identificadas como pertencentes a Gilda.

Essas informações de localização física, como o armário e a escrivaninha, foram possíveis de serem registradas devido a dois fatores importantes: a disponibilidade da família em receber na residência parte da equipe do Arquivo IEB/USP, que pôde fazer um mapeamento do apartamento do casal e a identificação dos locais de guarda física da documentação; e a proximidade entre o IEB/USP e o local de retirada, que facilitou o deslocamento das equipes. Seguindo as orientações técnicas da área, tenta-se, sempre que possível, na retirada de arquivos pessoais, seguir o seguinte protocolo:

[...] é recomendável a presença do profissional responsável pela organização do arquivo no recolhimento da documentação. Tal procedimento permitirá conhecer o(s) local(is) de guarda dos documentos antes de sua passagem para a instituição de memória, bem como observar, na hora da embalagem para a transferência, a disposição interna 
originária, detectando possíveis organizações dadas pelo titular durante a constituição de seu arquivo.

De preferência, não se devem desfazer prévias organizações antes da identificação completa do arquivo. Se, durante a transferência, não for possível manter os conjuntos e/ ou documentos da mesma forma que se encontram no seu local de origem, recomenda-se que estas informações sejam anotadas. (FRAIZ; COSTA, 2002, p. I5).

No caso dos arquivos pessoais de Gilda e Antonio Candido, portanto, diversos cuidados foram meticulosamente tomados, como o mapeamento do espaço e dos documentos e as necessárias transposições de anotações das informações de embalagens que precisaram ser posteriormente substituídas em ações de higienização e acondicionamento. Entretanto, veremos adiante que o tratamento dado ao arquivo de Gilda foi totalmente diferente daquele aplicado ao de Antonio Candido.

No caso do arquivo de Gilda, e finalizando a justificativa das medidas assumidas no protocolo de retirada, é importante relembrar que uma das figuras mais marcantes em sua vida e obra é Mário de Andrade. Na condição de prima do escritor, com quem morou dos I2 anos até se casar, Gilda conviveu no ambiente que guardava a vida privada de Mário assim como seus objetos de trabalho, tais como o piano, instrumento com o qual ministrava aulas, até sua biblioteca e documentos com os quais produzia sua obra. A casa de Mário de Andrade já foi espaço de muitos estudos5, e a própria Gilda nos conta:

[...] na rua Lopes Chaves, cursei o ginásio e a universidade, saindo de lá só no dia do meu casamento. [...]

A casa era muito estranha. Vista de fora, topograficamente, eu vivia no primeiro andar. Subia para o segundo só na hora de dormir. Embaixo, a rotina da casa era quase interiorana: Mariquinha, minha tia-avó, que eu chamava vovó Iaiá, sua irmã Nhanhã, Maria de Lourdes, irmã caçula de Mário, e Sebastiana, a cozinheira da vida inteira. [...] No mesmo espaço ficava o "meu escritório": a mesa de escrever (onde fazia minhas lições) e o piano. Na mudança do primeiro para o segundo lance da escada havia um quadro enorme, Futebol, de André Lhote. Eu ficava parada, completamente fascinada. Nesse ponto começava outra realidade. No segundo andar, à esquerda, começava o território de Mário de Andrade: o quarto, o estúdio, os livros, os quadros, a santarada dele, as peles de onça e os potes marajoaras que havia trazido do amazonas. (SOUZA, 20I4, p. 92).

Hoje, os estudos marioandradianos, especialmente aqueles desenvolvidos no IEB/USP e a partir do acervo do escritor, sob a guarda da instituição, mostram a importância de sua casa para a análise do colecionador, bibliófilo e arquivista Mário de Andrade. Livros e documentos trazem etiquetas que relacionam o tema de seu

5 Há estudos e vários produtos culturais produzidos sobre a casa. Dentre eles, destacamos o documentário $A$ casa de Mário, de 2013, dirigido por Luiz Bargman. 
interesse à topografia da casa. Em outras palavras: no caso de Mário, a disposição física de seus livros, documentos e obras de arte tinham sentido de ser e, sempre que possível, em seu processo de institucionalização, a chamada ordem original foi mantida ou relacionada à descrição documental.

Partindo deste pressuposto, isto é, o de que a organização dos objetos no espaço contém significados que podem vir a ser relevantes no momento da classificação arquivística, e levando também em conta a proximidade de Gilda e Antonio Candido com Mário de Andrade, nos pareceu que seria prudente mapear o apartamento do casal e relacioná-lo à guarda de seu arquivo, medida que já se mostrou útil ao longo do trabalho de classificação e que acreditamos que possa vir a ser útil para pesquisas futuras.

Passaremos agora a analisar a classificação do acervo de Gilda.

A classificação de arquivos pessoais a partir do método funcional gera para nós produtos como o que chamamos tecnicamente de quadro de arranjo, que é um dos vários instrumentos de organização de acervos e, consequentemente, pode tornar-se um importante instrumento de pesquisa. O quadro de arranjo é um mapa estilizado, no qual, no caso dos arquivos pessoais tratados pela equipe do IEB, grupos são delimitados. Dentro de tais grupos, poderão estar estruturados subgrupos, até chegarmos ao chamado nível do documento. Cada documento é descrito de forma individualizada. No caso de Gilda, o quadro de arranjo se concentrou nos seguintes grupos:

- Identidade civil

- Vida doméstica e familiar

- Formação

- Carreira docente e acadêmica - USP

- Relações sociais

- Produção literária e artística

- Participação em ações e associações culturais

- Pesquisa e produção intelectual

- Universo de interesses

Como dito, no caso do Fundo Gilda de Mello e Souza, cada grupo possui subgrupos, até que seja possível chegar aos documentos, ou seja, os grupos, tal qual um mapa, apresentam uma síntese de atividades desempenhadas por Gilda no decorrer de sua vida, e cada atividade abarca dentro de si uma reunião de itens documentais decorrentes das atividades que serviram de base classificatória.

É importante ressaltar que o presente ensaio é uma breve apresentação sobre o método aplicado ao acervo e sobre o seu conteúdo. Entretanto, instrumentos de pesquisa, como um guia individual para cada um dos fundos, estão sendo devidamente elaborados, nos quais são apresentados os passos decisórios da classificação documental. Assim as medidas tomadas acerca dos métodos de organização serão disponibilizadas ao público interessado, pois acreditamos que os instrumentos de pesquisa não são neutros, e as escolhas adotadas pela equipe interdisciplinar de 
organização do Fundo Gilda de Mello e Souza devem ser compartilhadas com o pesquisador ${ }^{6}$.

Voltando aos grupos, devemos perguntar: trata-se de uma classificação padrão aplicável a qualquer conjunto pessoal? A resposta é não!

Como dito anteriormente, no caso do arquivo pessoal de Gilda, decisões foram tomadas, muitas vezes visando, por exemplo, valorizar sua carreira como mulher intelectual. Além disso, o quadro de arranjo buscou auxiliar os pesquisadores interessados em ingressar na pluralidade de interesses e no pensamento refinado e "caleidoscópico" de Gilda de Mello e Souza. Seu processo de criação é multifacetado e segmentado. Temos um exemplo disso, a partir de carta de Io de agosto de I942, quando, ainda jovem, Gilda escreve a Mário de Andrade:

[...] eu guardo um certo pudor, um como que complexo de inferioridade artístico, sei lá, que me torna bastante difícil falar de meus escritos a pessoas já de celebridade como você. Talvez esse sentimento esteja ligado a, não propriamente descrença, mas a oposição que meus pais fizeram de início à minha "mania de escrever" e que, repudiada por mim, não deixou no entanto de me marcar. Sempre temo estar fazendo um papel ridículo me dando uma importância exagerada. [...] E prefiro calar sobre os escritos ainda em andamento, ainda não totalmente imaginados e definitivamente fixos. Porque, além do mais, sou duma assustadora mobilidade ou inconstância! Quantas vezes, escolhido o assunto pra um conto, vou no decorrer do mesmo mudando o rumo das coisas, a própria essência da história? Como contar a você, portanto, o que estou fazendo? Nem eu sei... [...] Você poderia me retrucar que esse processo de trabalho não impede o seu auxílio e que estava nas suas mãos evitar tamanho desperdício das minhas forças. - mas eu aprendo tanto perdendo tempo, Mário! Não pense que é soberba, Deus me livre! Mas sou um tanto... empírica no meu aprendizado e do mesmo modo que, quando estudava geografia, precisava não só ler mas repetir alto e escrever o nome da cidade, do rio, da montanha para gravar, agora preciso também realizar a experiência para lucrar com ela. (SOUZA, 20I4, p. 254-255).

Aqui vemos um esboço de seu processo de criação, que se firmará mais adiante, seja na breve produção ficcional publicada, seja na sua ampla produção acadêmica. A linha tênue entre elas é seu estilo marcante, e é por isso que identificamos que, na maioria de sua obra científica, Gilda lança mão de ensaios.

A respeito disso, aliás, Gilda diz ter abandonado a ficção, mas percebemos, tanto pela sua documentação, quanto pelo que aponta sua fortuna crítica, que isso não é totalmente verdade.

Em entrevista concedida a Augusto Massi, ela afirma:

6 Sobre tal tema, sugere-se a leitura de estudos que têm inspirado a revisão de protocolos técnicos de classificação e descrição documental pela equipe do Arquivo IEB/USP, como, por exemplo: Fox; Martínez-Ávila, Oliveira, 20I7; García Gutiérrez, 2013; Rodrigues, 2020. 
Eu fiquei dividida. Apesar de toda minha vida ter-se encaminhado para o ensino e para o ensaio, penso que não sufoquei inteiramente a minha personalidade ficcional. Digo isso por várias razões, entre elas, pela própria organização dos meus livros de crítica. A ficção sempre foi extremamente forte, não digo decisiva, se fosse eu teria sido ficcionista. A gente segue o rumo para o qual se prepara ou no qual se sente mais armada. (SOUZA, 20I4, p. 95-96).

Em carta a Ángel Rama, quando trabalham juntos na publicação de Macunaíma, pela Biblioteca Ayacucho, Gilda confessa ao amigo, quando entrega a introdução do livro e suas notas:

[...] Quanto à forma escolhida, intencionalmente de montagem, aparentemente neutra, com a violenta entrada final da voz fora do campo de Ungaretti, confesso que foi uma concessão ao meu temperamento de ficcionista a que eu não pude me furtar. (CANDIDO; RAMA, 20I8, p. 2I5-2I6).

Toda essa argumentação buscou chamar a atenção para a seguinte questão: no arquivo de Gilda de Mello e Souza, dentro do grupo Pesquisa e Produção Intelectual, há o subgrupo Ensaios. A escolha pela palavra ensaios para designar o subgrupo dialoga mais com a carreira e processo de criação de Gilda do que com a definição trazida pelo gênero textual. Nesse subgrupo estão textos dos mais diversos gêneros e extensões; alguns deles acabados, outros não; uns com mais de uma versão, outros com uma cópia da versão publicada e definitiva. Ou ainda: anotações de ideias; dossiês temáticos; textos que trazem páginas inseridas de outros textos, aproveitadas de arguições, palestras e aulas. Seu pensamento caleidoscópico está representado - e, podemos dizer, preservado - no subgrupo Ensaios. Para isso, buscamos, de forma atenta, manter a ordem original dos documentos encontrados na retirada do acervo, respeitando a organicidade dos papéis produzidos e acumulados por Gilda, a partir da consideração da pluralidade de seu pensamento. Esse conjunto de documentos, que foi um dos que nos tomou mais tempo de análise, nos provou que valeu a pena todo o trabalho da retirada controlada e meticulosa do acervo do apartamento do casal, bem como o necessário cuidado durante os processos de higienização e abertura para a classificação, já dentro do IEB/USP. Tal subgrupo, ordenado hierarquicamente no mesmo nível de agrupamentos como Estudos e Entrevistas, busca mostrar os bastidores da criação de Gilda.

Esperamos que este pequeno relato possa ter aguçado o interesse dos pesquisadores por outras partes do arquivo que também lançam nova luz sobre a vida e obra de Gilda de Mello e Souza.

\section{O Fundo Antonio Candido}

No período que vai da morte de Antonio Candido, em maio de 20I7, ao seu centenário, em 20I8, houve uma série de eventos e iniciativas em torno da memória do professor, sendo uma das mais abrangentes a edição do livro Antonio Candido Ioo anos, da 
Editora 34, organizada por Maria Augusta Fonseca e Roberto Schwarz. Em texto publicado nesse livro, Schwarz comenta as homenagens em curso, traçando um breve perfil do amigo:

Tudo isso é um pouco surpreendente pois quem conheceu Antonio Candido sabe que ele era um homem sobretudo discreto, que não gostava de aparecer nem mandar. No sentido convencional, o contrário de um político. Não obstante, está claro também que ele era agudamente político, só que de um modo pouco usual, digamos construtivo. Em vez do papel de porta-bandeira, ou de agitador na linha de frente, ele preferia a atuação de base, a função modesta de professor que ajuda os alunos a progredir, que dá aulas ao mesmo tempo acessíveis e extraordinárias, que organiza seminários para melhorar o nível de seu partido político, que faz propostas inovadoras de organização universitária, nas quais se evitam as irracionalidades cometidas anteriormente etc. etc. (SCHWARZ, 20I8, p. 72).

Esse aspecto político da prática de Antonio Candido, no qual se combinam modéstia, funcionalidade e alto nível, nas palavras de Schwarz (20I8), é nítido para aqueles que tiveram a oportunidade de trabalhar com seu arquivo pessoal, no que diz respeito tanto ao modo de acumulação quanto à forma como ele foi organizado pelo próprio titular - uma demonstração de sua consciência da importância da preservação de documentos para que a posteridade possa fazer releitura das histórias e da História.

Mantidos, em sua grande maioria, em pastas etiquetadas ao longo de décadas, os papéis de Antonio Candido documentam alguns dos aspectos relembrados por Schwarz como, por exemplo, seus planos de curso, dentre os quais podemos citar "Realidade e irrealidade na ficção", de I966-I967, e sua atuação militante, a respeito da qual podemos relembrar o processo de formação da Adusp, a Associação de Docentes da USP, em I977, ou o seminário "Socialismo e democracia", organizado para o Partido dos Trabalhadores já no início do século XXI. Encontram-se ainda entre os documentos textuais do Fundo Antonio Candido as notas de pesquisa para redação de boa parte da sua obra de crítica literária e sociológica, assim como alguma coisa de sua correspondência, com destaque para a troca de cartas com Mário de Andrade.

$\mathrm{O}$ arquivo do professor, no entanto, não se resume ao seu período de vida, contendo ainda muitos documentos relativos a seus antepassados maternos e paternos, documentos estes que remontam a meados do século XIX, com especial destaque para as fotografias, nas quais podemos observar várias gerações e as mudanças de costumes e hábitos de famílias das camadas médias do sudeste brasileiro na virada do século XIX para o XX. O interesse de Candido pelos antepassados fica nítido no arquivo, que possui ainda anotações acerca de genealogia.

Nesse sentido, para além dos campos principais de atuação de Antonio Candido, tais como a sociologia, a crítica literária, o magistério e sua atuação militante, o arquivo apresenta ainda parte da vida doméstica e familiar e dos universos de interesse do professor, que incluem tanto as histórias de família citadas acima, quanto a música e o cinema, esses dois últimos podendo ser pesquisados por meio das coleções de vinis e fitas cassete ou VHS e DVDs, respectivamente. 
No que tange à metodologia de organização do arquivo, é importante relembrar o que já foi dito anteriormente a respeito do mapeamento efetuado na residência do titular antes que o material fosse transferido para o IEB/USP. Nessa etapa foi possível identificar parte da relação de Antonio Candido com os documentos, localizando os papéis relativos à produção intelectual metodicamente organizados em pastas, no quarto dos fundos de seu apartamento; a grande maioria das fotografias acumuladas no armário de seu quarto de dormir; boa parte dos itens que tratavam dos antepassados reunida no armário do corredor. De forma que, buscando respeitar o princípio segundo o qual "o arquivo, por suas próprias coordenadas de definição, é uma reunião orgânica: seu acervo faz-se natural e cumulativamente" (BELLOTTO, 2006, p. 40), os dados acerca da disposição dos documentos em seu local de origem foram inclusos no momento do cadastro do material. Atentas à teoria arquivística, buscamos respeitar, no processo de institucionalização do arquivo de Antonio Candido, sobretudo os princípios de proveniência, organicidade e cumulatividade7.

Entretanto, é importante destacar que, no caso de Antonio Candido, não foi difícil seguir e aplicar tais princípios, pois ele, em vida, ordenou seus documentos para uso próprio de tal maneira, que, após sua morte, a manutenção deles foi simples para as equipes de tratamento documental. Ao contrário do arquivo de Gilda, no qual se notou o ressignificado de funcionalidades do mesmo documento, em Antonio Candido a grande dificuldade foi a grande massa documental produzida, acumulada e colecionada em uma vida de mais de 98 anos.

Assim, na etapa de classificação dos documentos, a equipe de cadastro do Fundo Antonio Candido buscou se guiar por dois critérios básicos: respeitar ao máximo a organização encontrada no apartamento do professor, tendo em vista que ele mantinha um controle metódico de seus papéis; e classificar os documentos por grupos funcionais que refletissem as diversas áreas de sua vida e pudessem estruturar o quadro de arranjo, proporcionando um instrumento de consulta acessível às mais diversas naturezas de pesquisadores. Os grupos funcionais que formam o quadro de arranjo do Fundo Antonio Candido são: Docência, Documentação Póstuma, Finanças, Formação, Identidade Civil, Militância, Produção Intelectual, Relações Sociais, Universo de Interesses e Vida Doméstica e Familiar. Estes, por sua vez, se dividem em subgrupos, orientados, sempre que possível, pelas anotações do titular nas embalagens originais.

Observando o segundo nível de classificação do grupo Docência, por exemplo, é possível notar que, para além da relação com a Universidade de São Paulo (USP)

7 Em Arquivos permanentes: tratamento documental, Heloisa Bellotto (2006, p. 88) define os princípios arquivísticos da seguinte maneira: "Princípio da Proveniência: Fixa a identidade do documento, relativamente a seu produtor. Por este princípio, os arquivos devem ser organizados em obediência à competência e às atividades da instituição ou pessoa legitimamente responsável pela produção, acumulação ou guarda dos documentos. Arquivos originários de uma instituição ou de uma pessoa devem manter a respectiva individualidade, dentro de seu contexto orgânico de produção, não devendo ser mesclados a outros de origem distinta. Princípio da Organicidade: As relações administrativas orgânicas se refletem nos conjuntos documentais. A organicidade é a qualidade segundo a qual os arquivos espelham a estrutura, funções e atividades da entidade produtora/acumuladora em suas relações internas e externas. [...] Princípio da Cumulatividade: $\mathrm{O}$ arquivo é uma formação progressiva, natural e orgânica”. 
e a Faculdade de Assis, atual Universidade Estadual Paulista (Unesp), nas quais foi professor, Antonio Candido estabeleceu colaboração com muitas outras instituições de ensino no Brasil - tais como a Pontifícia Universidade Católica (PUC), a Universidade Estadual de Campinas (Unicamp), a Universidade Federal de São Carlos (UFSCar), a Universidade Federal do Paraná (UFPR) e a Universidade Federal do Rio de Janeiro (UFRJ) - e no exterior, como a Universidad de la Republica (Udelar, Paraguai) e as universidades de Cornell, Harvard, Indiana, Stanford, Sorbonne, Wisconsin e Yale.

Já no grupo Militância, no qual podemos encontrar os documentos relativos à Adusp e ao seminário "Socialismo e democracia", citados anteriormente, é possível identificar, por meio do mesmo método de análise do segundo nível do grupo: a atuação de Antonio Candido na Comissão de Justiça e Paz e na Comissão Teotônio Vilela de Direitos Humanos; um dossiê dedicado ao caso Vladimir Herzog; sua relação com a Esquerda Democrática, o Movimento Democrático Brasileiro (MDB), o Partido Socialista Brasileiro (PSB), a União Democrática Socialista (UDS), além, evidentemente, do Partido dos Trabalhadores (PT); as trocas com a Faculdade de Direito da USP, o Instituto Lula, o Movimento dos Trabalhadores Rurais Sem Terra (MST) e a TVT (Rede de Comunicação dos Trabalhadores), entre outros. Cabe destacar, dentre os conjuntos classificados no grupo Militância, aquele denominado Livro Branco, contendo os documentos que relatam o conflito estudantil ocorrido na Rua Maria Antônia em outubro de I968.

Em Produção Intelectual encontramos, além de seus ensaios, artigos e livros, a colaboração com a Biblioteca Ayacucho, os artigos publicados na Folha da Manhã, além de entrevistas, discursos, testemunhos e palestras. Estão também no grupo Produção Intelectual o trabalho nas revistas Argumento e Clima e no Suplemento Literário do jornal $O$ Estado de S. Paulo. E, concluindo esta breve descrição de alguns grupos funcionais que estruturam o quadro de arranjo do Fundo Antonio Candido, lembremos o grupo Universo de Interesses, no qual estão localizadas as coleções de discos e cartões-postais, guias de viagem, documentos sobre as cidades de Cássia, Poços de Caldas e Paris e os papéis acerca da relação com Cuba, entre vários outros temas de seu interesse.

Relembrando Vinícius Dantas, na apresentação do livro Textos de intervenção (CANDIDO, 2002), quando ele diz que "O conjunto de materiais aqui reunidos compõe um livro sobre um escritor intelectualmente destemido, que atravessou o século XX assumindo posições radicais com tal nitidez e uma coerência tão firme, que é um mistério a se decifrar" (DANTAS, 2002, p. Io), podemos afirmar que o arquivo pessoal de Antonio Candido revela as características citadas por Dantas, e convidamos estudantes e pesquisadores a consultarem seus documentos em busca de decifrar os mistérios que eles guardam.

\section{CONSIDERAÇõES FINAIS}

Embora tenham sido tratados como dois fundos individuais, visando à rápida abertura para consulta pública, os arquivos de Gilda de Mello e Souza e Antonio Candido nos colocaram questões como: o álbum de fotografias da família na casa de Poços de Caldas, organizado por Gilda, não deveria também constar do Fundo 
Antonio Candido? E os filmes e discos colecionados ao longo da vida, a qual dos dois fundos deveriam estar vinculados?

Aparentemente, itens colecionáveis, como livros, filmes e discos de música, costumam apresentar a dubiedade da proveniência, afinal, nem sempre é possível determinar preferências inequivocamente. Apesar dos estudos sobre Fred Astaire de Gilda, Antonio Candido não seria também um apreciador de musicais?

Poderíamos presumir que são dilemas que caracterizam, principalmente, itens colecionáveis, ou seja, itens adquiridos coletivamente, e não produzidos pelo casal, de forma coletiva? Mas novamente nos perguntamos: onde ficariam os álbuns de fotografias da família? Às equipes que atuam com arquivos pessoais, especificamente arquivos pessoais de casais, qual seria um princípio técnico e ético adequado a seguir quando se trata do álbum de casamento ou das fotografias dos filhos? A quem atribuí-las?

O que o presente ensaio buscou demonstrar é que, por mais que se tenha tentado aplicar as técnicas e os princípios arquivísticos com o rigor que eles devem ser aplicados, e mesmo obedecendo a máxima de que arquivos pessoais são arquivos e como tais devem ser tratados, no caso de arquivo de casais, há uma lacuna metodológica que precisa ser enfrentada e discutida na busca da elaboração de instrumentos de pesquisa mais íntegros e honestos para com os dados a serem apresentados aos pesquisadores.

Essas e outras questões estão sendo refletidas em trabalho de doutoramento de uma das autoras deste artigo. Elas não são simples e não estão resolvidas. Mas serão desenvolvidas por meio de um estudo de caso que propõe a aplicação de uma metodologia de organização conjunta de arquivos pessoais de casais, tendo como base o precioso acervo de Gilda de Mello e Souza e Antonio Candido.

\section{Agradecimentos}

Agradecemos de forma especial a todas as equipes que integraram o projeto de organização dos fundos Gilda de Mello e Souza e Antonio Candido: Denise de Almeida Silva, supervisora técnica do Serviço de Arquivo IEB/USP; Adriano de Castro Meyer, Patrícia Godoy Gomes Dolay e Paulo José de Moura, técnicos do Arquivo IEB/ USP; Alexandre Macedo Ferreira, da área administrativa do IEB/USP; Guilherme Maranhão, responsável pela reprodução do acervo fotográfico em arquivos digitais; as consultoras de restauro do acervo fotográfico e textual, respectivamente, Luciana Amaral e Marlene Laky; os documentalistas Beatriz Aranha, Karoliny Aparecida de Lima Borges, Lucas Marcondes de Moura, Luciana Arcilla Negrini Silva, Marcelo Tanami, Marco Antonio Teixeira Jr., Matheus de Paula Silva e Viviane Vitor Longo; os estagiários Eduardo Macena e Maria Clara Toledo Paniago; a bolsista Michele da Silva Soares; os voluntários Anna Luiza de Araújo Silva, Daniel Arantes, Edmara Cristina Padovan Lanza, Denise Malta de Andrade, Gustavo Henrique Carvalho Fagundes, Juliana Siqueira, Mariana Pereira Massafera, Mariana Nogueira e Max Gimenes; os professores Aracy Amaral, Ana Paula Simioni e Marcos Antonio de Moraes. Agradecemos de forma especial também aos coordenadores e às equipes do 
Itaú Cultural. Registramos que somos apenas duas vozes de um imenso coro dedicado ao trabalho de valorização da história e da memória do Brasil. Acreditamos que só a harmonia do trabalho coletivo propiciou a abertura, em tão pouco tempo, para a pesquisa pública dos milhares de documentos que integram os fundos Gilda de Mello e Souza e Antonio Candido.

\section{SOBRE AS AUTORAS}

ELISABETE MARIN RIBAS é doutoranda pelo Programa de Pós-Graduação em Ciência da Informação da Universidade Estadual Paulista (Unesp) e especialista em Organização de Arquivos pelo Instituto de Estudos Brasileiros da Universidade de São Paulo (IEB/USP), onde compõe a equipe técnica de funcionários do Serviço de Arquivo. elisabete.ribas@usp.br https://orcid.org/oooo-oooI-89I8-8676

LAURA ESCOREL é mestre em História da Arte pela Universidade Federal de São Paulo (Unifesp); especialista em Gestão de Bens Culturais pela Fundação Getúlio Vargas (FGV); coordenadora do Projeto de Organização do Arquivo de Gilda de Mello e Souza e Antonio Candido no IEB/USP. lauraescorel@gmail.com https://orcid.org/o0oo-0002-6292-I02X

\section{REFERÊNCIAS}

BELLOTTO, Heloísa Liberalli. Arquivos permanentes: tratamento documental. Rio de Janeiro: Editora FGV, 2006.

CAMARGO, Ana Maria de Almeida; GOULART, Silvana. Tempo e circunstância: a abordagem contextual dos arquivos pessoais - procedimentos metodológicos adotados na organização dos documentos de Fernando Henrique Cardoso. São Paulo: Instituto Fernando Henrique Cardoso, 2007.

CANDIDO, Antonio. Textos de intervenção. Seleção, apresentação e notas de Vinícius Dantas. São Paulo: Duas Cidades: Editora 34, 2002. (Bibliografia de Antonio Candido). ; RAMA, Ángel. Conversa cortada: a correspondência entre Antonio Candido e Ángel Rama - o esboço de um projeto latino-americano I960-I983. Edição, prólogo e notas: Pablo Rocca; tradução dos textos em espanhol: Ernani Ssó. Rio de Janeiro: Ouro sobre Azul; São Paulo: Edusp, 2018. 
DANTAS, Vinícius. O modo de organizar. In: CANDIDO, Antonio. Textos de intervenção. Seleção, apresentação e notas de Vinícius Dantas. São Paulo: Duas Cidades: Editora 34, 2002, p. 9-II. (Bibliografia de Antonio Candido).

FOX, Melodie J.; MARTÍNEZ-ÁVILA, Daniel; OLIVEIRA, Suellen Milani. A interseccionalidade e o respeito às pessoas na organização do conhecimento. In: ALVES, Marcos Antonio; GRÁCIO, Maria Claudia Cabrini; MARTÍNEZ-ÁVILA; Daniel (Org.). Informação, conhecimento e modelos. Campinas: Unicamp, Centro de Lógica, Epistemologia e História da Ciência; Marília: Oficina Universitária, 20I7, p 239-253. (Coleção CLE, v. 78).

FRAIZ, Priscilla Moraes Varella; COSTA, Célia Maria Leite. Como organizar arquivos pessoais: manual. São Paulo: Arquivo do Estado e Associação de Arquivistas de São Paulo, 200I.

GARCÍA GUTIÉRREZ, Antonio. La organización del conocimiento desde la perspectiva poscolonial. Itinerarios de la paraconsistencia. Perspectivas em Ciência da Informação, v. I8, n. 4, dez. 20I3, p. 93-III.

PONTES, Heloísa. Intérpretes da metrópole: história social e relações de gênero no teatro e no campo intelectual, I940-I968. São Paulo: Edusp/Fapesp, 2010.

RODRIGUES, Aldair. Humanidades digitais e diáspora africana: questões éticas e metodológicas na elaboração de uma base de dados sobre a população escravizada de Mariana (século XVIII). Revista Estudos Históricos, Rio de janeiro, v. 33, n. 69, p. 64-87.

SCHWARZ, Roberto. Antonio Candido. In: FONSECA, Maria Augusta; SCHWARZ, Roberto (Org.). Antonio Candido Ioo anos. São Paulo: Editora 34, 2018.

SOUZA, Gilda de Mello e. A palavra afiada. Organização, introdução e notas de Walnice Nogueira Galvão. Rio de Janeiro: Ouro sobre Azul, 20I4. 